Bjørg Oddrun Hallås

Høgskulen på Vestlandet

Eli Kristin Aadland

Høgskulen på Vestlandet

Tom Lund

Høgskulen på Vestlandet

DOI: http://dx.doi.org/10.5617/adno.6097

\title{
Oppfatninger av natur i planverkene for kroppsøving og mat og helse i femårige grunnskolelærerutdanninger
}

\section{Sammendrag}

Artikkelen tar utgangspunkt i at bærekraftig utvikling er vedtatt som tverrfaglig tema i norsk skole (grunnopplceringen) og i de femårige grunnskolelcrerutdanningene. Som lcererutdannere og skoleforskere tilknyttet forskergruppen Nature in Children's Literature and Culture, ved Høgskulen på Vestlandet (HVL), er vi opptatt av miljødebatten og oppfatninger av natur i planverkene for de femårige grunnskolelærerutdanningene i fagene kroppsøving og mat og helse. De nasjonale studieplanene for 2017-18 og emneplaner fra fem UH-institusjoner utgjør vårt empiriske materiale. Vi har identifisert ord og begrep om miljødebatten og natur med analyseverktøyet NVivo. Funnene viser at ordene klima, menneske, naturen, ressurs og ute er lite brukt i planene, men selve meningskonteksten ordene står i kan tolkes som en noe menneskesentrert måte å forstå naturen på, et antroposentrisk syn. Ordene bcerekraft og friluftsliv forekommer flere ganger i planene og representerer både et antroposentrisk syn og en mer økosentrisk, helhetlig måte å tenke liv og omverden på. Vi diskuterer våre funn opp mot The Nature in Culture Matrix. Drøftingene konkluderer med at det er behov for forskning som også studerer ulike undervisningspraksiser og lærerutdanneres, praksislcereres og studenters egne erfaringer med utdanningene sett fra et miljøperspektiv. Vårt mål er at artikkelen kan bidra i en bevisstgjøring og refleksjon omkring hvordan man kan legge opp til mer økokritisk undervisning i fagene kroppsøving og mat og helse i norsk larerutdanning.

Nøkkelord: grunnskolelcererutdanninger, kroppsøving, mat og helse, natur, bœrekraftig utvikling, miljødimensjonen 


\title{
Concepts of Nature in the Physical Education and Food and Health Curricula in the Five-year Teacher Education Programmes
}

\begin{abstract}
This article takes as its starting point the decision that sustainable development is to be an interdisciplinary theme in Norwegian primary and secondary education and in the five-year teacher education programmes. As teacher educators and education researchers in the research group Nature in Children's Literature and Culture, at the Western Norway University of Applied Sciences, we are concerned about the environment debate and how nature is perceived in the plans for teacher education in two subject areas: Physical Education, and Food and Health. Our empirical material consists of the national study plans for 2017-18 and the course plans from five tertiary institutions. We have identified words and phrases related to the environmental dimension and nature using the analytical tool NVivo. The findings show that the words climate, people, nature, resource and outdoors are seldom used in these plans. Moreover, the contexts in which these words are used can be interpreted as indicating a human-centred view of nature, an anthropocentric view. The words sustainable and outdoor recreation (friluftsliv) occur numerous times in the plans, and represent both an anthropocentric view of nature and an ecocentric perspective, a more holistic way of thinking of life and the environment. We discuss our findings in relation to the Nature in Culture Matrix. The discussion concludes that there is a need for more research focusing on various teaching practices and on the experiences of teacher trainers, practice teachers and students in these subject areas, viewed from an environmental perspective. The objective of the article is to contribute to awareness raising and encourage reflection regarding strategies for more ecocritical teaching in the subjects Physical Education and Food and Health in Norwegian teacher education.
\end{abstract}

Keywords: teacher education, physical education, food and health, nature, sustainable development, environment

\section{Innledning}

Bærekraftig utvikling er vedtatt som ett av tre tverrfaglige tema i norsk skole, grunnopplæringen (Kunnskapsdepartementet, 2017). I norsk lærerutdanning skal studentene kvalifiseres til å ivareta utdanning for bærekraftig utvikling, et tverrfaglig tema som skal gi studentene forskningsbasert kunnskap om klima og miljø, og kompetanse i å støtte elevenes læring om, holdning til og handling for en bærekraftig utvikling (Nasjonalt råd for lærerutdanning, 2016a, 2016b). Deler 
av arbeidet for en bærekraftig utvikling handler om miljødimensjonen, altså det å ta vare på naturen og klimaet som en fornybar ressurs for mennesker (FNsambandet, 2018).

Tanken om å ivareta miljøet fordi det har verdi for mennesker, er tydelig i Brundtland-kommisjonens definisjon av bærekraft fra 1987, hvor det står: «Humanity has the ability to make development sustainable to ensure that it meets the needs of the present without compromising the ability of future generations to meet their own needs» (World Commission on Environment and Development, 1987, s. 16). I dette ligger et tydelig antroposentrisk perspektiv, menneskers behov er overordnet resten av naturens (Hverven, 2018; Hallås, Heggen, Rimmereide \& Schwebs, 2017). Flere har hevdet at hvis vi skal klare å gjøre noe med klimakrisen, må vi slutte å plassere mennesket i sentrum av universet (Vetlesen, 2015; Vetlesen \& Willig, 2018). Vetlesen har vist at ledende vestlige tenkere de siste hundreårene har legitimert overutnyttelsen av naturen, og han peker på at økonomiske og kulturelle strukturer har bidratt til vår tids krise mellom samfunn og natur. Han kaller det en menneskesentrert mentalitet, en antroposentrisme som gjennomsyrer alt vi gjør (Vetlesen, 2015).

Et annet perspektiv på bærekraft enn det antroposentriske kan være å ta utgangpunkt i naturens gjensidige avhengighet, som kalles et økosentrisk perspektiv (Heggen, 2015). Her settes økosystemenes behov i sentrum - ikke menneskets. Det er lenge siden Næss (1976) i sin dypøkologiske bevegelse var tydelig på at arten og størrelsen av menneskets inngrep i naturen er etisk uforsvarlig, og at en vesentlig bedring forutsetter endring av økonomiske, teknologiske og ideologiske forhold. Mennesket er en del av naturen og alt liv har egenverdi, sier Næss, ikke bare med bakgrunn i hvilken verdi det har for mennesket (1976).

Barn og unge skal verne om naturen og dens goder i fremtiden. Goga (2016) hevder at det er behov for et økosentrisk perspektiv på arbeid med bærekraftig utvikling og fremhever at de som skal utdanne barn og unge til en miljø- og språkbevisst fremtid, har et stort ansvar. Wolla (2015), som har forsket på 15åringers holdninger til klima- og miljøutfordringer, etterlyser handlekraft i klimadebatten, spesielt fra skoleforskere og skolepolitikere. Straume (2017) trekker fram utdanningsfeltet som sentralt.

Som skoleforskere forsker vi på didaktiske praksiser ute i natur- og kulturlandskap og på miljødimensjonen av bærekraftig utvikling. Vi er tilknyttet forskergruppen Nature in Children's Literature and Culture (NaChiLitCul) (http://blogg.hvl.no/nachilit/) ved Høgskulen på Vestlandet. Som lærerutdannere underviser vi kroppsøvingsstudenter og mat og helsestudenter som skal ut i skolen og utdanne barn og unge til en miljø- og språkbevisst fremtid. Vi arbeider med forskning og undervisning hvor natur er tema: i natur, fra natur og med natur (Hallås \& Karlsen, 2015). Hvordan man som del av ulike didaktiske praksiser i våre fag oppfatter og erfarer bærekraftsbegrepet, miljødebatten og natur er viktig 
å løfte fram, snakke om og diskutere. Hvordan vi gjennomfører undervisning og måten vi bruker naturen på, har store konsekvenser for både natur og mennesker.

Refleksjoner mellom lærere og lærende er en forutsetning for å kunne avgjøre om man skal endre handlinger eller fortsette med praksiser man allerede driver med. I en lærerutdanningskontekst handler dette om innholdet i utdanningene, et innhold som bestemmes av styringsdokumenter og ulike planer, men også av hvordan planene oppfattes, gjennomføres og erfares av dem som bruker dem.

Vårt ståsted er at vi ser på mennesket som en del av naturen, og vi støtter oss til Næss (1976) sin formulering om at alt liv har egenverdi, ikke bare med bakgrunn i hvilken verdi det har for mennesket. Vi er nysgjerrige på om det i lærerutdanningene er en menneskesentrert mentalitet, en antroposentrisme som gjennomsyrer alt vi gjør. Denne artikkelen belyser derfor de femårige grunnskolelærerutdanningene i Norge med et spesifikt blikk på de nasjonale studieplanene i fagene kroppsøving og mat og helse - det formelle læreplannivået - og emneplanene i de to fagene ved fem utvalgte lærerutdanningsinstitusjoner - altså det oppfattede læreplannivået.

Mange ulike begrep er i omløp når temaet er bærekraftig utvikling, noe som kommer tydelig fram når vi skal redegjøre for forskning på feltet og vår egen studie. Vi er opptatt av miljødimensjonen av bærekraftig utvikling og av natur. I tillegg ønsker vi å bruke økokritikk som begrep og vi har et økokritisk perspektiv i lesing av emneplaner i fagene kroppsøving og mat og helse. Forskningsspørsmålet er: Hvordan kommer oppfatninger av natur til uttrykk i de skriftlige planverkene for de femårige grunnskolelærerutdanningene i fagene kroppsøving og mat og helse? Vårt mål er at artikkelen kan bidra til en diskusjon blant lærerutdannere om hvordan planverkene skal oppfattes og at både lærerutdannere og studenter kan delta i refleksjon og bevisstgjøring omkring hvordan de oppfattede læreplannivåene skal operasjonaliseres for å få til en mer økokritisk undervisning i fagene.

Det er lite forskning som har analysert plandokumenter på høyere utdanningsnivå for faget kroppsøving, og for faget mat og helse finnes det ingenting. Moen og Frenning (2015) har utforsket planverket i 30 studiepoeng kroppsøving i grunnskolelærerutdanning 1.-7. trinn med fokus på koblingen mellom teori og praktisk aktivitet, samt lærerstudenters analytiske og refleksive kompetanse. Læreplanstudier på de nye femårige grunnskolelærerutdanningene i lys av miljødimensjonen og med en økokritisk tilnærming finnes ikke.

\section{Miljødebatten og natur i en utdanningskontekst}

Den moderne miljødebatten startet med Rachel Carsons bok Silent Spring (1962) om menneskenes angrep på naturen gjennom forurensing. Mer enn femti år etter er vi på kanten av en global økokrise, sier Hareide (2018) som hevder at 
løsningene på hvordan vi skal få til en økologisk helhetstenkning har en spennvidde fra teknoromantikk til naturromantikk. Norges forskningsråd (NFR) ønsker med programmet SAMKUL forskning som belyser de kulturelle forutsetningene for våre forhold til naturen, blant annet til våre naturomgivelser. NFR er tydelig på at også et kulturperspektiv er nødvendig for å kunne forstå og håndtere de store utfordringene i form av blant annet klimaendringer, forurensning, redusert artsmangfold, press på matproduksjon, ressurstilgang og -fordeling (Forskningsrådet, 2011). Studier av lærerutdanningene er vårt kulturperspektiv og et svar på NFRs forskningsanbefaling.

Bærekraftig utvikling benyttes som begrep i skole og lærerutdanning og er vedtatt som et tverrfaglig tema. Det dreier seg om store områder som økonomi, klima og miljø, og sosiale forhold, og FNs 17 bærekraftsmål er trukket fram (FNsambandet, 2018). Når man er opptatt av miljødebatten, blir natur et sentralt begrep. Natur kan være et språklig begrep, kulturelle forestillinger, og det kan være konkrete steder, noe rent fysisk (Williams, 1983). Natur som noe konkret kan forstås som samspill mellom alle levende vesener og miljøet (Hverven, 2018). Natur som en fysisk størrelse kan også forstås som landskapsformasjoner, vann, jord, luft og fjell, altså en konkret opplevelses-, dannings- og læringsarena i ulike skole- og lærerutdanningsfag (Hallås \& Karlsen, 2015; Karlsen, 2015).

Naturopplevelser i småbarnsalderen er trukket fram som avgjørende for senere holdning til og handling for natur og miljøvern (Carson, 1962; Chawla, 1998, 1999; Marion \& Strømme, 2008). I norske barnehager har det vært fokus på å oppleve natur snarere enn å jobbe bredere med bærekraft og miljøspørsmål, hevder Heggen (2015). Det har imidlertid vært vanskelig å påvise at det å være i natur har betydning for utvikling av holdninger og handlinger for miljøet, fordi det er avhengig av mange sammenhengende faktorer og omstendigheter (Rajecki, 1982; Kollmuss \& Agyeman, 2002; Sandell \& Öhman, 2010). Ungdom har selv trukket fram skolen som en av de viktigste kildene hvor de henter kunnskap om klima og klimaendringer (Fløttum, Rivenes \& Dahl, 2014). Kunnskap og holdninger fører likevel ikke automatisk til endret atferd (Kollmuss \& Agyeman, 2002). Straume (2017) trekker fram at mangelen på handlingsmuligheter, ikke dårlige holdninger eller verdier, er den største hindringen for en mer bærekraftig utvikling.

Læreres oppfatninger av klima, miljø og deres tilhørende undervisningspraksiser er viktig å få kunnskap om for å forstå hvilke faktorer som også danner barns og unges miljøbevissthet, hevder Sobel (1996), Jordet (2007) og Quinn, Castéra og Clément (2016). Jordet (2010) har trukket fram betydningen av en opplæring som er opplevelses- og erfaringsbasert og handlingsrettet. Jordet (2010) hevder at en utdanning for bærekraftig utvikling forutsetter at lærere og elever retter blikket ut av klasserommet og bruker skolens omgivelser som ressurs i opplæringen. For å kunne handle etisk og miljøbevisst hevder han at naturen og samfunnet må benyttes som kunnskapskilde og læringsarena, og at det må etableres samarbeid med lokale instanser. Etter FNs utdanningstiår for 
bærekraftig utvikling (2005-2014) viste likevel studier på norsk ungdomsskole at det er lite fokus på temaet bærekraft i undervisningen (Wolla, 2015). Lærere benyttet seg i liten grad av anbefalte undervisningsmetoder og hjelpemidler når de planla sin undervisning for bærekraftig utvikling, og de svarte at både læreplanen og kollegaer ga lite veiledning (Wolla, 2015). Det har også vist seg vanskelig å ta tak i miljøspørsmål mer spontant i ulike undervisningssituasjoner ute i naturen (Hallås, Sæle \& Løtveit, 2017).

I en utdanningskontekst er miljødimensjonen knyttet til både fag og emner, men Sinnes og Straume (2017), som diskuterer bærekraftig utvikling som fagovergripende tema i grunnopplæringen, presiserer at det er helt avgjørende at temaet ikke kun behandles der det utgjør en sentral del av et faglig innhold, men bør behandles som vesentlig i seg selv. Innenfor utdanningsfeltet er natur knyttet til ulike fag og emner, men i noen fag har natur i større grad enn andre fag en sentral plass, som for eksempel i fagene kroppsøving og mat og helse. I høyere utdanning er kroppsøving og mat og helse to av undervisningsfagene lærerstudenter kan velge i en femårig grunnskolelærerutdanning.

\section{Femårige grunnskolelærerutdanninger}

Høsten 2017 startet det første kullet lærerstudenter i de femårige grunnskolelærerutdanningene (GLU) rettet mot 1.-7. trinn og 5.-10. trinn. Utdanningene er masterutdanninger med syklus 1 (tre år), og syklus 2 (to år) med fordypning i masterfaget. Universitet og høgskoler (UH) avgjør selv modell for når de enkelte skole- og lærerutdanningsfagene skal tilbys og om fagene tilbys som masterfag. Utdanningene er bygget opp med læringsutbytteformuleringer som sier noe om hva studentene skal oppnå av kunnskap, ferdigheter og generell kompetanse for utdanningene som helhet og for hvert fag (Kunnskapsdepartementet, 2016a, 2016b). De enkelte UH-institusjonenes programplaner skal sikre at studentene får undervisning i følgende fellesemner: Globalt medborgerskap og det flerkulturelle samfunnet, Psykososialt leringsmiljø, Samiske forhold og samiske elevers rettigheter, Bœrekraftig utvikling og Estetiske læeringsprosesser (Nasjonalt råd for lærerutdanning, 2016a, 2016b). Institusjonene bestemmer selv når i studieløpet fellesemnene tas opp, og når et eventuelt samarbeid mellom fagmiljøene innenfor fellestemaene kan skje. Utdanningene skal være integrerte; dette betyr samarbeid mellom fag og kombinasjon av teori og praksis. Tidligere forskning på Grunnskolelærerreformen fra 2010 viste at faglærere ved de ulike UHinstitusjonene ønsket et tettere samarbeid mellom fagene for å håndtere og implementere fellestema (Haara \& Jensen, 2013).

To av undervisningsfagene studenter kan velge, er Kroppsøving og Mat og helse. Hvert fag kan tas som 15+15 sp eller 30 sp i syklus 1 med mulighet for 30 sp påbygging slik at studenten kan velge ett av fagene som masterfag. Fagenes egenart handler blant annet om utvikling av praktiske ferdigheter, og fagene har 
en historisk danningstradisjon hvor kombinasjon av praktisk og teoretisk kunnskap har vært sentral (Holthe, Hallås, Styve \& Vindenes, 2013). I kroppsøving er naturen en viktig lærings- og danningsarena i friluftsliv, i ulike idretter, i utendørsaktiviteter og i uteskole. En diskusjon om tema knyttet til bærekraftig fysisk aktivitet, utstyr og ressursbruk er løftet fram i fagmiljøene (Bjørnarå, Torstveit, Stea \& Bere, 2016). I mat og helse er miljøspørsmål, ressursbruk og bærekraft aktuelle tema i de nye GLU-utdanningene der sanking fra naturen og tilberedning av mat i naturen kan inngå som didaktiske aktiviteter.

\section{Plandokumenter som tekster med kulturelle uttrykk}

De enkelte UH-institusjonene som tilbyr grunnskolelærerutdanninger, er kunnskapsinstitusjoner med emneplaner utviklet med utgangspunkt i Forskrift om rammeplan for grunnskolelærerutdanning for trinn 1-7 og 5-10 (Kunnskapsdepartementet, 2016a, 2016b) og Nasjonale retningslinjer for grunnskolelærerutdanningen trinn 1-7 og 5-10 (Nasjonalt råd for lærerutdanning, 2016a, 2016b).

Vi ser på plandokumentene som en type tekster som virker i kulturen og i samfunnet, altså i utdanningsfeltet og i norsk lærerutdanning. Planene er tekster med ord og begrep og et språk som trer fram i dokumentene i form av innhold, læringsutbytteformuleringer og vurderingsformer.

Alle typer tekster vil på en eller annen måte romme nedarvede tankefigurer og språklige bilder som påvirker og former vår forståelse av verden, hevder Goga (2016) og Nyrnes (2017). Styringsdokumentene for de femårige lærerutdanningene er utformet i en tid, i en kultur, med en særegen sjanger eller form, og av mennesker med sine forforståelser, faglige bakgrunner og verdimessige standpunkt. Planverkene er uttrykk for hva som vektlegges fra myndighetene og hva som vektlegges ved de enkelte høgskolene og i fagmiljøene som har vært med å utvikle emneplaner. Ord og begrep er uttrykk for en bestemt måte å beskrive et fenomen på, men må ikke betraktes som rene fakta eller sannhet, men heller som en sosial og språklig konstruksjon. Corneliussen og Dyb (2017) hevder at meningskonstruksjoner ikke er nøytrale eller uskyldige, de har effekter i samfunnet, de påvirker. Vi ser på studieplaner som meningskonstruksjoner som har effekter og påvirker utdanningsfeltet, lærerutdanningene, skolen og videre i samfunnet. Studieplaner kan ses på som en sosial konstruksjon, en bestemt måte visse begrep er beskrevet på, eller ikke beskrevet.

Goga (2016) trekker fram, med referanser til Mortensen (2013), at litteratur enten kan opprettholde en menneskesentrert måte å forstå natur på, eller den kan utfordre og endre den til en mer helhetlig måte å tenke miljø på, det vil si dyr, planter og mennesker som likeverdige liv. Vi tenker at dette også kan gjelde andre kulturuttrykk, som planverk eller praksiser, ikke bare litteratur. Å utforske måter å forstå natur på i kultur er for oss en økokritisk tilnærming. 


\section{Et økokritisk perspektiv}

Et økokritisk perspektiv eller en økokritisk tilnærming undersøker fremstillingen av natur og av menneskenes plass i naturen i litteratur eller andre kulturuttrykk (Garrard, 2012). Kulturuttrykk kan være mye forskjellig - som ulike typer tekster, film eller andre kunstuttrykk, digitale apper eller didaktiske praksiser. Det å bli dannet økokritisk betyr å kunne stille spørsmål ved menneskets privilegerte plass i naturen (Haraway, 2007; Garrard, 2012; Goga, Guanio-Uluru, Hallås \& Nyrnes, 2018). Røskeland (2018) trekker fram at et mål for den økokritisk orienterte litteraturundervisningen er å få større bevissthet og refleksjon omkring natur og naturopplevelser og videre hvordan mennesker, dyr, planter og omgivelsene blir fremstilt og formidlet gjennom litteratur. Røskeland (2018) trekker videre fram at innenfor litteraturteori handler økokritisk lesing om at litteratur kan ha samfunnsmessig relevans og påvirkningskraft. Hun refererer til Stueland (2016) når hun trekker fram hvordan et økokritisk perspektiv på natur skiller seg fra andre tilnærminger til natur i litteratur. Naturen i seg selv er interessant, hevder hun, som biologi, geologi, som en tilstand, klima eller fenomen, altså ikke bare som scene eller uttrykk for noe annet (Røskeland, 2018). Nyrnes (2017) presiserer at et økokritisk perspektiv er «retta mot litteratur, men også utover litteraturen, slik litteratur verkar i kulturen og samfunnet, gjennom eit slikt perspektiv spør ein kva påverknad ein tekst kan ha» (s. 271).

En økokritisk tilnærming i kroppsøving og mat og helse handler om å utforske fremstillingen av natur, og av menneskenes plass i naturen, i fagenes ulike kulturuttrykk som didaktiske praksiser, aktiviteter og handlinger, ulike typer skriftlige tekster som er knyttet til fagene eller muntlige uttrykk. I økokritikken er man opptatt av hvilke ord og begrep som blir brukt om natur og naturelement, og av hva som skjer i møtet mellom tekst og leser, mellom undervisningspraksis og den lærende, eller mellom kulturuttrykk og lærerstudent. Kroppsøving og mat og helse har ulike kulturelle uttrykk som kan ha forskjellige tankefigurer om natur, enten feirende - da vektlegges idyll og et romantisk syn på forholdet mellom menneske og natur - eller kanskje et mer problematiserende syn som vektlegger menneskets rovdrift på natur. Tankefigurene som dominerer i fagene kan være med å forme praksisene og forme en bevissthet om natur, om miljø og om forholdet mellom menneske og natur.

\section{Å studere studieplaner}

Sørensen og Fugl Eskjær (2014) hevder at et viktig bidrag i klimaforskningen er forskningsbidrag fra humaniora, som handler om å undersøke hvordan vår forståelse og fortolkning av blant annet natur setter rammer for politiske og administrative tiltak når det gjelder miljøutfordringer. I en lærerutdannings- 
kontekst kan dette handle om å undersøke de politisk vedtatte styringsdokumentene for lærerutdanningene og hvordan de enkelte institusjonene forstår og tolker begrep i egne emneplaner.

Planverkene setter rammer og skal gi retning for den kunnskap, de ferdigheter og den generelle kompetansen som studentene trenger for senere å støtte elevenes læring om, holdning til og handling for en bærekraftig utvikling (Nasjonalt råd for lærerutdanning 2016a, 2016b). Goodlad (1979) beskriver forløpet fra overordnet læreplan til virkeliggjort undervisningspraksis. De fem læreplannivåene vil på hver sin måte si noe om læringsarbeidet i skole eller høyere utdanning. De er I) den ideologiske, II) den formelle, III) den oppfattede, IV) den gjennomførte, og V) den erfarte læreplan.

Det språket, de ord og de begrep som brukes i planverkene for fagene kroppsøving og mat og helse har innvirkning på hvordan både lærerutdannere og studenter tenker om og handler når det gjelder miljødimensjonen og natur. Goga (2016) fremhever at miljøbevissthet også handler om språkbevissthet. Hun poengterer at håndteringen av vår tids miljøutfordringer avhenger av hvordan språk former debatten. Derfor mener vi at det er viktig å utforske ord og begrep om miljø og natur som lærerutdannere og studenter møter i planverkene. Med Goodlad (1979) sitt begrepsapparat stiller vi spørsmål til det vi finner ved å undersøke de ulike læreplannivåene. Hva står i de nasjonale studieplanene (det formelle læreplannivået), hva har universitet og høgskoler skrevet i emneplanene i fagene (det oppfattede læreplannivået), hvordan blir selve undervisningen gjennomført (det operasjonelle læreplannivået), og selvsagt hvordan opplever studentene eller lærerutdannerne undervisningen (den erfarte læreplanen)? Denne artikkelen begrenser seg til å studere det formelle og det oppfattede læreplannivået.

\section{Materiale og metode}

Datamaterialet vårt består av Forskrift om rammeplan for grunnskolelærerutdanning for trinn 1-7 og 5-10, heretter kalt Forskrift (Kunnskapsdepartementet, 2016a, 2016b), og Nasjonale retningslinjer for grunnskolelærerutdanningen trinn 1-7 og 5-10, heretter kalt Nasjonale retningslinjer (Nasjonalt råd for lærerutdanning, 2016a, 2016b). I tillegg består materialet av et utvalg emneplaner i fagene kroppsøving og mat og helse i de nye femårige grunnskolelærerutdanningene, fra universitet og høgskoler som høsten 2017 hadde emneplaner tilgjengelig på internett.

$\mathrm{Vi}$ foretok et systematisk søk på nettsidene til alle lærerutdanningsinstitusjonene i Norge (Utdanningsdirektoratet, 2017) for å få oversikt over institusjonene som tilbød de nye femårige grunnskolelærerutdanningene fra 1 . august 2017. I rapporten «Styrking av de praktisk-estetiske fagene i lærerut- 
danningene» svarte 11 institusjoner at de skulle tilby de nye femårige grunnskolelærerutdanningene i praktiske og estetiske fag (Aadland et al., 2017). Av de 11 institusjonene var det 8 som tilbød både kroppsøving og mat og helse i nye femårige GLU. Ved å søke på internett på de 8 institusjonene kom det fram at oppbyggingen av studiemodellene i de nye femårige GLU var forskjellige på de ulike institusjonene. Flere institusjoner tilbød kroppsøving og mat og helse i andre eller tredje året i studieløpet, syklus 1 . Institusjonene i vårt utvalg bestod av alle institusjonene som hadde fagplaner tilgjengelig for både kroppsøving og mat og helse i femårige GLU i perioden 20. september til 5. oktober 2017. Det var 5 institusjoner med geografisk spredning som inngikk i utvalget. Institusjonene er anonymisert, tilfeldig plassert og heretter kalt UH1, UH2, UH3, UH4 og UH5.

For å kunne undersøke hvordan natur er oppfattet i de skriftlige planverkene for de femårige grunnskolelærerutdanningene i fagene kroppsøving og mat og helse, startet vi med en hermeneutisk, kvalitativ nærlesning av disse planverkene eller tekstene. Smith (2016) definerer nærlesing som en nøyaktig og oppmerksom lesing i tråd med de spørsmål man er interessert i å finne svar på. Vi leste hver for oss og deretter kollektivt for å få et første inntrykk og for å lete etter ord og begrep i tråd med vårt forskningsspørsmål. I vårt arbeid med bærekraftig utvikling var vi klar over at det var mange begrep i omløp. I fellesskap noterte vi ned ord og begrep i relasjon til temaet bærekraft som vi fant ved vår første gjennomlesning, men også begrep vi vet brukes i feltet. Vi valgte så en innholdsanalyse av planverkene og støttet oss til Fauskanger og Mosvold (2014) som fremhever innholdsanalysens muligheter i utdanningsforskning. De legger vekt på at en slik kvalitativ metodisk tilnærming i studier av skriftlig datamateriale kan ha ulike tilnærminger: summativ, konvensjonell og teoridrevet.

I den første analysefasen startet vi med en summativ innholdsanalyse hvor vi søkte etter bestemte ord og deres forekomst i tekstmaterialet, ved hjelp av det digitale analyseverktøyet NVivo 11 for Windows (QSR International Pty Ltd, 2017). Med bakgrunn i vårt arbeid i feltet, i vår forskergruppe og vår første individuelle og kollektive nærlesing av datamaterialet, kom vi fram til følgende 26 ord som representative for miljødebatten: natur, naturen, klima, klimendring, forurensing, bœrekraft, bœrekraftig, bœrekraftighet, miljø, økologiske, økologi, økokritisk, landskap, kulturlandskap, omgivelser, menneske, menneskelig, ressurs, ressurser, ressurstilgang, ressursfordeling, ute, friluftsliv, uteskole, sanking, miljøbevisste. Av disse nøkkelordene var det sju treff i materialet: bœrekraft, friluftsliv, klima, menneske, naturen, ressurs og ute. Videre ble ordene først identifisert for å finne i hvilke plandokumenter de var brukt (tabell 1) og deretter hvordan ordene fordelte seg i emneplanene fra de fem UH-institusjonene (tabell 2). Deretter benyttet vi ordtrær fra NVivo for å få et første innblikk i konteksten. I tråd med Grønmo (2004) er en slik analyse av kvalitative data vanlig når man arbeider med tekster, og han fremhever at det er nødvendig å trekke ut et utvalg. Vårt utvalg var ord, men vi kunne ha valgt andre tilnærminger som for 
eksempel korte eller lengre tekstutkast. En styrke med et utvalg er etterprøvbarheten sier Grønmo (2004), og det var også viktig for oss.

Vi fortsatte med en konvensjonell innholdsanalyse hvor vi i fellesskap prøvde å bedre forstå ordenes meningskontekst innenfor miljødimensjonen. Vi gikk da etter hvert vekk fra ordtrær og foretok en grundigere og nøyaktig lesing av alle ordenes plassering i alle dokumentene for å lete etter mulige kategorier som kunne fungere i videre analyse. Hsieh og Shannon (2005) og Fauskanger og Mosvold (2014) trekker fram at slike tilnærminger kan gi en dypere forståelse av materialet. Ord og begrep er uttrykk for et budskap, men vi er klar over at ord og begrep på et slikt overflatenivå kan skjule andre budskap eller perspektiv. Vi var tre forskere fra to ulike fagfelt som sammen arbeidet med analysene, noe vi ser på som en styrke.

En teoridrevet innholdsanalyse er av Fauskanger og Mosvold (2014) beskrevet som en tilnærming hvor man benytter en allerede utviklet teori eller et eksisterende teoretisk rammeverk. For vårt materiale valgte vi derfor The Nature in Culture Matrix (figur 1) som analysemodell, et økokritisk rammeverk som bygger på teori om hvordan natur er fremstilt i kulturen (Goga et al., 2018). Matrisen er utviklet i forskergruppen NaChiLitCul hvor vi har en kontinuerlig utprøving av matrisens potensial som analytisk verktøy for å forstå fortolkningene av natur og klima slik de kommer til uttrykk i materialet (Goga et al., 2018). Matrisen ble derfor styrende for hvordan vi bedre kunne utforske vårt materiale og si noe om bruken av ordene og sammenhengen ordene står i. Grønmo (2004) fremhever at å benytte en matrise kan være et viktig hjelpemiddel for om mulig å identifisere og synliggjøre mønstre eller sammenhenger i materialet.

The Nature in Culture Matrix har to akser. Den horisontale aksen spenner mellom en antroposentrisk, menneskesentrert måte å forstå natur på, der natur blir forstått som at den dekker menneskets behov, og en økosentrisk, helhetlig måte å tenke om liv på (Quinn et al., 2016). Den vertikale aksen spenner mellom en feirende holdning til natur som for eksempel vakker, smakfull, idyllisk eller verdifull, og en problematiserende holdning som kan handle om at natur er fremstilt som ødelagt eller noe om natur som farlig eller problemfylt.

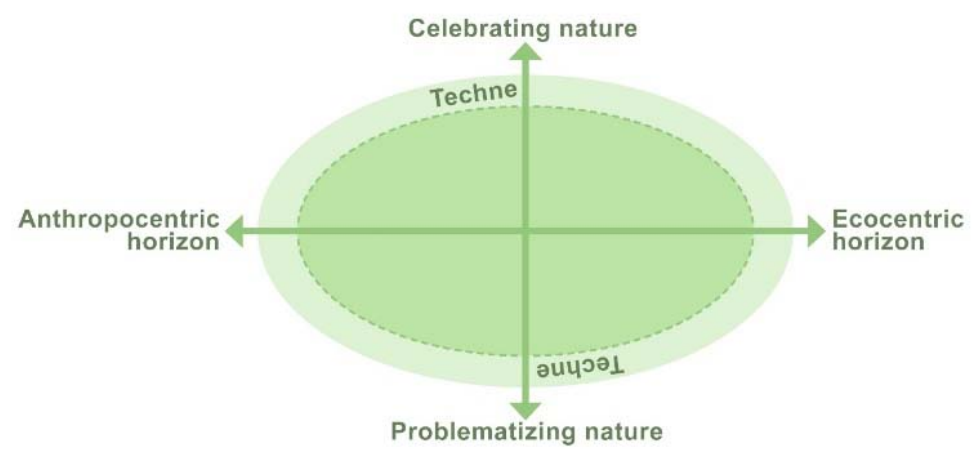

Figur 1. The Nature in Culture Matrix (Goga et al., 2018)

Matrisen har vært benyttet i analyser av litterære tekster (Birkeland, 2016; Nyrnes, 2017; Røskeland, 2018), i utforsking av ungdoms egne utsagn om klimalitteratur 
(Goga, 2016), i analyser av barns egne muntlige beskrivelser i møte med natur i barnehage og skole (Hallås \& Heggen, 2018), i observasjonsstudier av læreres undervisningspraksis (Hallås, Sæle \& Løtveit, 2017) og med økokritiske perspektiv på barns tekster og kultur sett i et nordisk perspektiv (Goga et al., 2018).

\section{Ordtreff i plandokumentene}

Basert på analysene presenterer vi først en kvantitativ oversikt (tabell 1) som viser antall treff på ordene bœrekraft, friluftsliv, klima, menneske, naturen, ressurs og ute i Forskrift om rammeplan for grunnskolelærerutdanningene for trinn 1-7 og 5-10 (Forskrift) og i Nasjonale retningslinjer for grunnskolelærerutdanningene, trinn 1-7 og 5-10 (Nasjonale retningslinjer) - disse representerer det formelle læreplannivået - og videre i emneplanene for fem UH-institusjoner, det oppfattede læreplannivået. I det formelle læreplannivået ble ordene identifisert i studienes fellesemner, og vi fikk treff for fagene naturfag, kunst og håndverk, samfunnsfag, kroppsøving, og mat og helse.

Tabell 1. Oversikt over antall treff på ordene bcerekraft, friluftsliv, klima, menneske, naturen, ressurs og ute i Forskrift om rammeplan for grunnskolelærerutdanningene for trinn 1-7 og 5-10 (Forskrift), i Nasjonale retningslinjer for grunnskolelærerutdanningene, trinn 1-7 og 5-10 (Nasjonale retningslinjer), og i emneplaner i kroppsøving (Krøv) og mat og helse (M \& H) ved fem lærerutdanningsinstitusjoner

\begin{tabular}{lccccccc}
\hline Søkeord & \multicolumn{4}{c}{ Forskrift } & \multicolumn{2}{c}{ Nasjonale retningslinjer } & \multicolumn{2}{c}{ Emneplaner } \\
& Totalt & GLU 1-7 & GLU 5-10 & GLU 1-7 & GLU 5-10 & Krøv & M \& H \\
\hline Bærekraft & 37 & 1 & 1 & 7 & 8 & - & 20 \\
Friluftsliv & 72 & - & - & 4 & 4 & 64 & - \\
Klima & 5 & - & - & - & 3 & 2 & - \\
Menneske & 12 & - & - & 4 & 4 & - & 4 \\
Naturen & 15 & - & - & 5 & 6 & - & 4 \\
Ressurs & 21 & 1 & 1 & 8 & 9 & - & 2 \\
Ute & 8 & - & - & 1 & 1 & 4 & 2 \\
\hline
\end{tabular}

I tabell 2 vises en oversikt over antall treff kun for emneplanene i kroppsøving (Krøv) og mat og helse (M \& H) ved de fem lærerutdanningsinstitusjonene, det oppfattede læreplannivået. Et tydelig hovedfunn her er at mange av ordene forekommer relativt få ganger og at de alle bare i liten grad er knyttet til miljødimensjonen og natur.

Tabell 2. Oversikt over antall treff på ordene bcrekraft, friluftsliv, klima, menneske, naturen, ressurs og ute i emneplaner i kroppsøving (Krøv) og mat og helse (M \& H) ved fem lærerutdanningsinstitusjoner

\begin{tabular}{lccccccc} 
& Bærekraft & Friluftsliv & Klima & Menneske & Naturen & Ressurs & Ute \\
\hline UH1 & 8 & 9 & - & - & 4 & 2 & 2 \\
UH2 & 2 & 14 & 2 & - & - & - & - \\
UH3 & 4 & 17 & - & - & - & - & - \\
UH4 & - & 10 & - & - & - & - & - \\
UH5 & 6 & 14 & - & 4 & - & - & 4 \\
\hline Totalt & 20 & 64 & 2 & 4 & 4 & 2 & 6 \\
\hline
\end{tabular}


Vi presenterer nå ord for ord og viser først hvordan ordene er representert i studieplanene, det formelle og det oppfattede læreplannivået (tabell 1), og deretter kun i emneplanene, det oppfattede læreplannivået (tabell 2).

Det ordet som er nevnt flest ganger er friluftsliv; det forekommer 72 ganger i de formelle og oppfattede planene. Av 64 treff på ordet friluftsliv i emneplanene i kroppsøving er det kun UH2 som i læreplan i kroppsøving for 5-10. trinn har knyttet friluftsliv til miljødiskursen med følgende utbytteformulering: «Har forståelse for sammenhengen mellom klima og miljøutfordringer og friluftsliv og bevegelsesaktivitet.» I emneplanene og forskriftene viser ellers friluftsliv til aktiviteten, og ikke til verdien og miljødiskursen knyttet til det. Ved UH4 er friluftsliv beskrevet i GLU 5.-10. trinn under kunnskap hvor det står at studentene skal ha «forståelse for og kan reflektere over kulturelle endringer i syn på friluftsliv». Friluftsliv er ikke nevnt i noen emneplaner i mat og helse.

Ordet bcerekraft ga 37 treff. I Nasjonale retningslinjer for både 1.-7. trinn og 5.-10. trinn står det:

Bærekraftig utvikling: Utdanningen skal kvalifisere studenten til å ivareta utdanning for bærekraftig utvikling som et tverrfaglig tema. Utdanningen skal gi forskningsbasert kunnskap om klima, miljø og utvikling og kompetanse i å støtte elevenes læring om, holdning til og handling for en bærekraftig utvikling. (Nasjonalt råd for lærerutdanning, 2016a, 2016b)

At ordet bærekraft fikk svært mange treff, skyldes at bærekraftig utvikling er et fellesemne som alle studentene skal ha som del av grunnskolelærerutdanningene. Svært mange av treffene i de formelle læreplanene er fra læringsutbytteformuleringene i fagene kunst og håndverk (fem treff) og naturfag (åtte treff). Når det gjelder søk i emneplanene, er det interessant å registrere at bærekraft kun forkommer i emneplanene for faget mat og helse fra fire UHinstitusjoner, men ikke i kroppsøving for noen av institusjonene. To UHinstitusjoner trekker fram bærekraft sammen med velsmakende og trygg mat, mens UH1 under kunnskap har skrevet at studentene skal «diskutere etiske og samfunnsmessige dilemmaer rundt bærekraftig matforbruk».

Ordet ressurs var det tredje mest benyttede ordet av våre sju, med 21 treff. De fleste treffene handler ikke om naturens ressurser. I de Nasjonale retningslinjene, beskrivelsene om utdanningenes innhold, fant vi treff som kan plasseres innenfor miljødebatten. For samfunnsfag 5.-10. trinn står det følgende: «ha kunnskap om klima, miljø, ressurs og ressurskonflikter nasjonalt og internasjonalt». I emneplanene for kroppsøving finner vi ikke ordet ressurs brukt. I mat og helse er det nevnt to ganger i emneplanene til UH1 for både 1.-7. og 5.-10. trinn hvor det under ferdighet står: «Kan lage mat ute i naturen og bruke naturen som ressurs.»

Ordet naturen ga 15 treff, men er ikke benyttet i Forskriften, kun i de Nasjonale retningslinjene for naturfag og mat og helse hvor det for både 1.-7. og 5.-10. trinn står: 
Samiske mattradisjoner, måltidsskikker og tradisjonelle måter å utnytte matressurser fra naturen skal integreres i faget.

I emneplanene er det kun i faget mat og helse på UH1 som ga treff, to for 1.-7. trinn og to for 5.-10. trinn: «Kan lage mat ute i naturen og bruke naturen som ressurs.» I eksemplene over ser vi at både ressurs og naturen er nevnt i samme utbytteformulering. I faget kroppsøving er ikke ordet naturen brukt noen steder i de formelle planverkene eller i emneplaner i faget.

Ordet menneske er ikke brukt i Forskriften, men åtte ganger i de Nasjonale retningslinjene, fire for 1.-7. trinn og fire for 5.-10. trinn. For kroppsøving er ordet menneske kun brukt i de nasjonale retningslinjene, hvor det i introduksjonen til faget står: «kroppslige dimensjonen ved det å være menneske». Ordet menneske er også brukt fire ganger i emneplan for mat og helse for UH5. Ved å analysere disse tekstene kan ikke bruken av ordet knyttes til miljødebatten.

Ute er et ord som ga åtte treff, to i de formelle læreplanene i naturfag og to i emneplanene i mat og helse for UH1, det samme som tidligere nevnt handler om å lage mat ute. I tillegg fant vi fire treff i emneplanene i kroppsøving for UH5 som handlet om praktisk undervisning inne og ute. I kroppsøving er ikke dette knyttet til noen føringer om hvor eller hvordan undervisning utendørs kan handle om miljødimensjonen.

Ordet klima ga totalt fem treff, hvorav to fra de formelle læreplanene, de Nasjonale retningslinjene for naturfag, og ett treff for samfunnsfag, altså ikke i kroppsøving eller mat og helse. I emneplanene for UH2 er ordet klima tatt med for kroppsøving 1, del 2, både 1.-7. og 5.-10. trinn. Det står under kunnskap at studenten skal: «Ha forståelse for sammenhengen mellom klima- og miljøutfordringer og friluftsliv og bevegelsesaktivitet.»

\section{Et økokritisk perspektiv på emneplaner i kroppsøving og mat og helse}

Hovedfunnene viser at ordene vi søkte etter, og som representerer miljødebatten og oppfatning av natur, forekommer relativt få ganger i emneplanene for kroppsøving og mat og helse. Forskriften og de Nasjonale retningslinjene fungerer som lovverk, og med vårt ordsøk og analyser ser vi at de fem utvalgte UH-institusjonene i all hovedsak er i tråd med loven. UH-institusjonene er frie til å utvikle egne emneplaner med utgangspunkt i de formelle planene, og noen institusjoner har også benyttet denne muligheten når de bruker ord, begrep og formuleringer som gir tydelige perspektiv for hva institusjonen ønsker studentene skal oppnå av kunnskap, ferdigheter og kompetanse.

Vi drøfter nå emneplanene for fagene kroppsøving og mat og helse, og tar utgangspunkt i de ulike posisjonene i The Nature in Culture Matrix når vi velger en økokritisk lesing. Det kan gi en bedre forståelse av hvordan natur er oppfattet i emneplanene. En økokritisk lesing kan også gjøre oss bevisst på emneplanene 
som styrende for undervisningsinnholdet i fagene. Kun videre forskning kan vise om den gjennomførte undervisningen, og erfaringer med den, kan danne grunnlag for studenters forståelse av miljødimensjonen som del av bærekraftig utvikling. Det er også viktig å være klar over at matrisen vi benytter, er en organisk tankefigur som stadig utvikles i dialog med et materiale.

En antroposentrisk, menneskesentrert, tilnærming handler her om at ord og deres meningskontekst i emneplanene er skrevet på en måte som setter menneskets behov først. Både kroppsøving og mat og helse er riktignok fag hvor den lærende skal utvikle seg som menneske, ta vare på kroppen og være en aktiv handlende medborger. I emneplanene vi har studert, kommer det menneskesentrerte tydelig til uttrykk der for eksempel bcerekraft er knyttet sammen med velsmakende mat, hvor maten for oss mennesker er i sentrum. Det kan tolkes som om planverkene støtter seg til Brundtland-kommisjonens definisjon av bærekraftbegrepet fra 1987, hvor bærekraft er definert som en utvikling som imøtekommer behovene til dagens generasjon uten å redusere mulighetene for kommende generasjoner til å dekke sine behov (World Commission on Environment and Development, 1987). Vi har tidligere problematisert denne definisjonen fordi den setter menneskets behov som overordnet resten av naturen (Hallås et al., 2017; Hverven, 2018). Bærekraft er ikke nevnt i kroppsøvingsfaget for noen av de fem UH-institusjonene, og det er tankevekkende.

Når friluftsliv er nevnt i planverkene for kroppsøvingsfaget, brukes det hovedsakelig om friluftslivsaktivitet, likestilt med idrett. Det er nevnt mange ganger, blant annet fordi friluftsliv har en sterk posisjon i faget. Friluftsliv er i noen tilfeller beskrevet sammen med uttrykk som «fremme bevegelsesglede», noe vi tolker som et feirende perspektiv med menneskets behov som førende. Et feirende syn på natur er ofte forankret i en forståelse av velbehag, noe uberørt og uskyldig (Goga, 2016). Også der friluftsliv og sikkerhet er nevnt i emneplanen for UH3, kan det umiddelbart tolkes som at sikkerhet gjelder for menneskene, ikke andre arter. Det er kun i én av emneplanene, UH2, at vi finner en økokritisk tilnærming; der settes friluftsliv i sammenheng med klima og miljøutfordringer. Ordet friluftsliv er ikke nevnt i faget mat og helse selv om sanking av næringsmidler og matauke ute har vært et sentralt kjennetegn for både et nyttefriluftsliv og et overskuddsfriluftsliv (Rafoss \& Seippel, 2016).

Goga (2016) og Nyrnes (2017) presiserer at alle tekster representerer nedarvede tankefigurer som påvirker og former vår forståelse av verden, noe vi har vært innom tidligere. Ordene og deres meningskontekst kan gi sterke føringer til de som skal bruke planene. Laclau og Mouffe (1985) snakker om en «indre homogenisering» når en diskurs fremstår som koherent og får et preg av å være objektiv og fastlåst, eller «sann». En diskurs oppnår en koherent mening ved at den meningen som blir tatt opp, tilpasses diskursen, mens alternative meninger utelates (s. 112). Friluftsliv som begrep brukes i offentlige dokumenter hvor diskursen eller tankesettet handler om menneskets frie liv ute i naturen, hvor frisk luft, bevegelse, folkehelse og det gode liv for menneskene er viktigst (Klima- og 
miljødepartementet, 2015). Vi finner den samme feirende diskursen på friluftsliv i emneplanene for kroppsøving og savner et mer problematiserende syn på friluftsliv og natur for framtidens lærere.

I Nasjonale retningslinjer for kroppsøving i GLU (Nasjonalt råd for lærerutdanning, 2016a, 2016b) brukes ordet menneske for å beskrive faget i fremtiden. Her trekkes de kroppslige dimensjonene ved det å være menneske fram, dette kan tolkes antroposentrisk fordi beskrivelsene av mennesket ikke handler om menneske som én av flere arter. I emneplanene vi utforsket er ikke ordet menneske brukt. $\AA$ avdekke dette ser vi på som viktig; det representerer et humanistisk forskningsperspektiv, slik Sørensen og Fugl Eskjær (2014) hevder er et viktig bidrag i klimaforskningen. Ingen steder i planene vi studerte har vi funnet at ordet menneske er brukt for å uttrykke noe som handler om menneskets plass i naturen, menneskers ansvar for naturen og miljøet, og at menneskenes livsgrunnlag er helt avhengig av naturen.

Ordet naturen er i vårt materiale funnet i emneplanene for mat og helse, og gitt mening i en kontekst hvor det er satt sammen med hvordan man kan utnytte matressurser fra naturen. Vi tolker fremstillingen som en menneskesentrert måte å forstå naturens ressurstilgang på. I sin ytterste konsekvens kan dette handle om overutnyttelse av naturen, men når Vetlesen (2015) beskriver overutnyttelsen eller rovdrift på naturen, snakker han om mer ekstreme forhold. Funnene i noen emneplaner beskriver at studentene skal lage mat ute i naturen. Dette er riktignok i tråd med anbefalinger fra Jordet $(2007,2010)$, som fremhever bruk av naturen som en lærings- og danningsarena. Utemåltidet som er brukt som begrep i planene er, slik vi tolker tekstene, fremstilt som kun naturfeirende i og med at det ikke trekkes fram noe om miljøhensyn. Som tidligere nevnt er ikke ordet naturen nevnt i noen av de fem UH-institusjonenes emneplaner for kroppsøving; det er viktig å merke seg, mener vi.

En økosentrisk tilnærming i vår studie handler om ord og deres meningskontekst i emneplanene, og hvordan de representerer et mulig helhetlig syn på alt liv, natur og våre ressurser. En økosentrisk forståelse er i tråd med Næss sine tanker om at alt liv har egenverdi (1976). En slik helhetlig tanke kommer til uttrykk i emneplanen for UH1 hvor det er presisert et etisk perspektiv på bærekraft i mat og helse. Emneplanen har beskrevet at studentene skal diskutere samfunnsmessige dilemmaer rundt bærekraftig matforbruk, noe vi tolker som et $ø$ kosentrisk perspektiv. Samtaler, refleksjoner og handlinger vil det være viktig at finner sted når vi vet at den økologiske krisen ikke bare er en krise i de fysiske omgivelsene, men like mye en sosial og kulturell krise (Bergthaller et al., 2014).

Våre funn viser at det flere steder i planene der ordet friluftsliv er benyttet, er nevnt nærfriluftsliv. Vi har tidligere sett at friluftsliv fremstilles som svært antroposentrisk, men med bruk av nærfriluftsliv velger vi å tolke dette som en mulig bevissthet om at det å benytte nærmiljøet vil innebære mindre forflytting med forurensende transport og muligens mer miljøvennlig undervisning. For å kunne si mer om dette vil det være behov for studier av gjennomført undervisning 
og studier som løfter fram erfaringer fra lærerutdannere, praksislærere og studenter. Bruk av nærfriluftsliv som begrep i lærerutdanningene må dessuten ses i sammenheng med at ordet er benyttet i Læreplanverket for kroppsøving i Kunnskapsløftet (Utdanningsdirektoratet, 2015) for de laveste trinnene og at friluftsliv i nærmiljøet er mer hensiktsmessig for den aldersgruppen.

Et annet økosentrisk perspektiv mener vi å lese i emneplanen for UH2 hvor friluftsliv er benyttet i kroppsøving, med en presisering om at studentene skal ha forståelse for sammenhengen mellom klima- og miljøutfordringer og friluftsliv og bevegelsesaktivitet. Dette kan se ut til å være i tråd med Næss’ (1976) økosofi der han er tydelig på at rikdommen av forskjeller mellom levende vesener ikke skal begrense menneskets muligheter for å utfolde sin egenart. Også Faarlund (1989) og Leirhaug (2010) har fremhevet at friluftsliv skal være opphold i naturen hvor man i tråd med naturens egne rytmer viser ydmykhet for naturmangfold og forankrer friluftslivsaktiviteter i et syn som representerer en mer økosentrisk tenkning. Næss selv fremhevet sterkt at det var «viktig å stake opp retningslinjer for etisk og økologisk ansvarsbevisst friluftsliv» (1976, s. 304).

Klimalitteratur er et begrep som Andersen (2014) bruker, og han beskriver det som tekster hvor den globale oppvarming, forårsaket av menneskers utslipp av drivhusgasser, er tema. Emneplanene vi har studert kan ikke sies å være klimalitteratur, blant annet fordi vi kun én plass i emneplanene finner ordet klima nevnt. En annen begrunnelse er emneplanenes manglende kritiske potensial for å alarmere leseren eller lede leseren til selvransakelse og selvkritikk (Goga, 2016). I emneplanen i kroppsøving for UH4 er det riktignok beskrevet at studentene skal ha forståelse for og kan reflektere over kulturelle endringer i syn på friluftsliv. Disse presiseringene i emneplanene har ikke utgangspunkt i de formelle planene, men kan si noe om fagmiljøenes mulige økosentriske ståsted ved de institusjonene som har utviklet planene. Om presiseringene i emneplanen får følger for gjennomført undervisning, vil være viktig å få mer kunnskap om. Ifølge Faarlund (1989) har friluftsliv et potensial til å være en vei til samfunnsendringer og miljøengasjement. Disse perspektivene er muligens ønsket fram igjen i planene for UH2 og UH4, men kun nye studier vil avdekke om det blir tilfelle.

\section{Oppsummerende avslutning}

Det har vært mulig å si noe om hvordan natur er oppfattet i de skriftlige planverkene for de femårige grunnskolelærerutdanningene i fagene kroppsøving og mat og helse. Vi mener at lærerutdanningene på alle læreplannivå må vende seg bort fra en antroposentrisk forståelse og til en forståelse av verden hvor det enkelte mennesket i større grad blir klar over at vi er en del av naturen. Slike tanker er tydelige hos Hausstätter og Sarromaa (2009) som hevder at man i skolen trenger en miljørettet pedagogikk som viser hvordan vår identitet som menneske er 
avhengig av miljøet vi er en del av. De ønsker å fremme en miljørettet pedagogikk med et økologisk naturperspektiv.

Vi inviterer til videre forskning innenfor utdanningsfeltet. Det er behov for forskning som undersøker om og hvordan bærekraftig utvikling og oppfatninger av natur blir en del av selve undervisningen i norsk lærerutdanning, og hvordan lærerutdanningene og kommende læreres arbeid i grunnopplæringen kan være med å forme barns og unges miljø- og språkbevissthet. Hvilke didaktiske valg som foretas og hvordan dette operasjonaliseres, vil være viktig å få mer kunnskap om. Både lærerutdannere, praksislærere og studenter må derfor delta i diskusjoner om hvordan planverkene skal forstås og operasjonaliseres, og diskusjonene må være utgangspunkt for bevisstgjøring og refleksjoner omkring en mer økokritisk undervisning i alle lærerutdanningsfag.

Bare gjennom refleksjoner over begrepsbruk og utforsking av alle læreplannivå vil vi kunne gi et større bilde av om lærerutdanningene preges av en menneskesentrert mentalitet og om det er en antroposentrisme i alt vi gjør. Det kan være stor avstand mellom det formelle læreplannivået og praksis eller gjennomført undervisning. Dette kan bety at UH-institusjonene som utdanner lærere i kroppsøving og i mat og helse, har en undervisningspraksis som tar opp miljødebatten i større grad enn hva vår studie av planverkene har vist, og at natur oppfattes på andre måter enn vi har drøftet her. Sentrale spørsmål man må kunne stille med utgangspunkt i fagenes formelle og oppfattede læreplannivå er for eksempel: Hvordan konkretiseres bærekraftsbegrepet i disse fagene? Hva er natur i disse fagene? For å svare på disse spørsmålene utfordrer vi alle lærerutdannere og studenter til sammen å lese, diskutere og reflektere over hvordan ord og begrep oppfattes og operasjonaliseres, og hvordan det igjen kan gi retning for en økokritisk undervisningspraksis i kroppsøving og i mat og helse.

I Norge pågår det nå en fagfornyelse i grunnopplæringen og Bærekraftig utvikling er vedtatt som ett av flere tverrfaglige tema. I ny overordnet del for grunnopplæringen i Norge er det presisert i kapittelet Respekt for naturen og miljøbevissthet at skolen skal bidra til at elevene utvikler naturglede, respekt for naturen og klima- og miljøbevissthet (Kunnskapsdepartementet, 2017). Dette tilsier at lærerutdanningene må ta ansvar for å utdanne lærere som kan hjelpe barn og unge til en miljøbevissthet som også handler om språkbevissthet.

\section{Om forfatterne}

Bjørg Oddrun Hallås er dosent i kroppsøving ved Høgskulen på Vestlandet. Hennes forskningsinteresser omfatter blant annet didaktiske praksiser med et særlig fokus på kroppsøvingsfaget.

Institusjonstilknytning: Institutt for idrett, kosthald og naturfag, Høgskulen på Vestlandet, 5020 Bergen.

E-post: boh@hvl.no 
Eli Kristin Aadland er førsteamanuensis i mat og helse ved Høgskulen på Vestlandet. Hennes forskningsinteresser omfatter blant annet mat og måltider i barnehage og skole.

Institusjonstilknytning: Institutt for idrett, kosthald og naturfag, Høgskulen på Vestlandet, 5020 Bergen.

E-post: eka@hvl.no

Tom Lund er høgskulelektor i idrett ved Høgskulen på Vestlandet. Hans forskningsinteresser omfatter blant annet friluftslivspedagogikk, kroppsøving, motorisk læring og friluftsliv, kultur og samfunn.

Institusjonstilknytning: Institutt for idrett, kosthald og naturfag, Høgskulen på Vestlandet, 6856 Sogndal.

E-post: tom.lund@hvl.no

\section{Referanser}

Andersen, G. (2014). Klimakrisen i litteraturen. I M. Sørensen \& M. Fugl Eskjær (red.), Klima og mennesker. Humanistiske perspektiver på klimaforandringer (s. 107-123). København: Københavns Universitet Museum Tusculanums Forlag.

Aadland, E. K., Borgen, J. S., Salvesen, G., Sæthre-McGuirk, E., Gjølme, E. G. \& Oftedal, K. H. (2017). Styrking av de praktiske og estetiske fagene i lererutdanningene. Rapport. Arbeidsgruppe nedsatt av NRLU. Hentet fra: https://www.uhr.no/_f/p1/if03b81a6-ddbb47b3-9f75-2c0c7a7cd781/rapport-styrking-av-de-praktiske-og-estetiske-fagene-ilarerutdanningene.pdf

Bergthaller, H., Emmett, R., Johns-Putra, A., Kneitz, A., Lidström, S., McCorristine, S., Ramos, I. P., Phillips, D, Rigby, K. \& Robin, L. (2014). Mapping Common Ground: Ecocriticism, Environmental History, and the Environmental Humanities. Environmental Humanities, 5(1), 261-276. Hentet fra: https://read.dukeupress.edu/environmentalhumanities/article/5/1/261/8152/Mapping-Common-Ground-Ecocriticism-Environmental

Birkeland, T. (2016). Forhandling om natur - kultur. En økokritisk lesning av Jörg Müller og Jörg Steiners bildebok Kaninliv (1978). Barnelittercert forskningstidsskrift, 7(1). Art. 1. doi: https://doi.org/10.3402/blft.v7.33705

Bjørnarå, H. B., Torstveit, M. K., Stea, T. H. \& Bere, E. (2016). Fysisk aktivitet er ikke nødvendigvis bærekraftig. Forskning.no. Hentet 10.01.2017 fra: http://forskning.no/meninger/kronikk/2016/05/fysisk-aktivitet-er-ikke-nodvendigvisbaerekraftig

Carson, R. (1962). Silent Spring. New York: Houghton Mifflin Company.

Chawla, L. (1998). Significant life experiences revisited: a review of research on sources of pro-environmental sensitivity. The Journal of Environmental Education, 29(3), 11-21.

Chawla, L. (1999). Life paths into effective environmental action. The Journal of Environmental Education, 31(1), 15-26.

Corneliussen, H. G. \& Dyb, K. (2017). Om teknologien som ikke fikk være teknologi diskurser om velferdsteknologi. I J. R. Andersen, E. Bjørhusdal, J. G. Nesse \& T. Årethun (red.), Immateriall kapital (kap. 9, s. 165-181). doi:

https://doi.org/10.18261/9788215028163-2017-09 
Fauskanger, J. \& Mosvold, R. (2014). Innholdsanalysens muligheter i utdanningsforskning. Norsk pedagogisk tidsskrift, 98(2), 127-139. Hentet fra: https://www.idunn.no/npt/2014/02/innholdsanalysens_muligheter_iutdanningsforskning

Fløttum, K., Rivenes, V. \& Dahl, T. (2014). Ungdommers forståelse av og holdninger til klima. NATUREN, 138(6), 242-249. Hentet fra: https://www.idunn.no/natur/2014/06/ungdommers_forstaaelse_av_og_holdninger_til_kli $\underline{\mathrm{ma}}$

FN-sambandet (2018). Bcerekraftig utvikling. Hentet fra: https://www.fn.no/Tema/Fattigdom/Baerekraftig-utvikling

Forskningsrådet (2011). Samfunnsutviklingens kulturelle forutsetninger (SAMKUL). Om SAMKUL. Hentet fra: https://www.forskningsradet.no/prognettsamkul/Artikkel/Om_SAMKUL/1253964698934

Faarlund, N. (1989). Friluftsliv - naturverd og endring med glede. I G. Andersen (red.), Momenter til en dypere naturvernforståelse (s. 88-97). Sandvika: Vett og viten.

Garrard, G. (2012). Ecocriticism. London and New York: Routledge.

Goga, N. (2016). Miljøbevissthet og språkbevissthet. Om ungdomsskoleelevers møte med klimalitteratur. Norsklcereren, 3, 60-72.

Goga, N., Guanio-Uluru, L., Hallås, B. O. \& Nyrnes, A. (2018). Ecocritical Perspectives on Children's Texts and Cultures: Nordic Dialogues. Palgrave Macmillan UK.

Goodlad, J. I. (1979). Curriculum inquiry: the study of curriculum practice. New York: McGraw-Hill book Company.

Grønmo, S. (2004). Samfunnsvitenskapelige metoder. Bergen: Fagbokforlaget.

Hallås, B. O. \& Karlsen, G. (2015). Innledning. I B. O. Hallås \& G. Karlsen (red.), Natur og danning. Profesjonsutøvelse, barnehage og skole (s. 13-21). Bergen: Fagbokforlaget.

Hallås, B. O., Heggen, M. P., Rimmereide, H. E. \& Schwebs, T. (2017). Barnet og bærekraften. Kronikk i Morgenbladet, 04.08.2017. Hentet 17.01.2018 fra: https://morgenbladet.no/ideer/2017/08/barnet-og-baerekraften

Hallås, B. O., Løtveit, K. \& Sæle, O. O. (2017). Natursyn en undervisningsdag på ungdomstrinnet - ved, på og i sjø. Vann, 52(3), 307-317. Hentet fra: https://vannforeningen.no/dokumentarkiv/natursyn-en-undervisningsdag-paungdomstrinnet-ved-pa-og-i-sjo/

Hallås, B. O. \& Heggen, M. P. (2018). «We are all nature» - young children’s expressions about nature. I N. Goga, L. Guanio-Uluru, B. O. Hallås \& A. Nyrnes (red.), Ecocritical Perspectives on Children's Texts and Cultures: Nordic Dialogues (s. 259-276). Palgrave Macmillan UK.

Hareide, D. (2018). Teknoromantikk. Klassekampen, 09.01.18.

Haraway, D. (2007). When species meet. Minneapolis: University of Minnesota Press.

Hausstätter, R. S. \& Sarromaa, S. (2009). Et teoretisk bidrag til en miljørettet pedagogikk. Norsk pedagogisk tidsskrift, 93(1), 67-76.

Heggen, M. P. (2015). Bærekraftig utvikling i norske barnehager - et spørsmål om naturfølelse? I B. O. Hallås \& G. Karlsen (red.), Natur og danning. Profesjonsutøvelse, barnehage og skole (s. 117-135). Bergen: Fagbokforlaget.

Holthe, A., Hallås, O., Styve, E. T. \& Vindenes, N. (2013). Rammefaktorenes betydning for tilretteleggingen av opplæringen i de praktisk-estetiske fagene - en casestudie. Acta Didactica Norge, 7(1), Art. 13. doi: http://dx.doi.org/10.5617/adno.1118

Hsieh, H.-F. \& Shannon, S. E. (2005). Three approaches to qualitative content analysis. Qualitative Health Research, 15(9), 1277-1288. doi: https://doi.org/10.1177/1049732305276687

Hverven, S. (2018). Naturfilosofi. Oslo: Dreyers forlag. 
Haara, F. O. \& Jensen, E. S. (2013). Grunnleggende ferdigheter i grunnskolelærerutdanningen. Uniped, 36(1), 102-114.

Jordet, A. N. (2007). Ncrmiljøet som klasserom. En undersøkelse om uteskolens didaktikk i et danningsteoretisk og erfaringsteoretisk perspektiv. Doktoravhandling, Universitetet i Oslo. Oslo: Unipub forlag.

Jordet, A. N. (2010). Klasserommet utenfor: Tilpasset opplering i et utvidet læringsrom. Oslo: Cappelen Akademisk forlag.

Karlsen, G. (2015). Natur og danning. I B. O. Hallås \& G. Karlsen (red.), Natur og danning. Profesjonsutøvelse, barnehage og skole (s. 21-37). Bergen: Fagbokforlaget.

Klima- og miljødepartementet (2015). Friluftsliv - Natur som kilde til helse og livskvalitet. (Meld. St. 18, 2015-2016). Hentet fra https://www.regjeringen.no/contentassets/9147361515a74ec8822c8dac5f43a95a/no/pdfs/s tm201520160018000dddpdfs.pdf

Kollmuss, A. \& Agyeman, J. (2002). Mind the Gap: Why do people act environmentally and what are the barriers to pro-environmental behavior? Environmental Education Research, 8(3), 239-260. doi: https://doi.org/10.1080/13504620220145401

Kunnskapsdepartementet (2016a). Forskrift om rammeplan for grunnskolelærerutdanning for trinn 1-7. Hentet fra: https://lovdata.no/dokument/SF/forskrift/2016-06-07-860

Kunnskapsdepartementet (2016b). Forskrift om rammeplan for grunnskolelcrerutdanning for trinn 5-10. Hentet fra: https://lovdata.no/dokument/SF/forskrift/2016-06-07-861

Kunnskapsdepartementet (2017). Overordnet del - verdier og prinsipper for grunnopplaringen. Hentet 10.08.2018 fra:

https://www.regjeringen.no/contentassets/37f2f7e1850046a0a3f676fd45851384/overordn et-del---verdier-og-prinsipper-for-grunnopplaringen.pdf

Laclau, E. \& Mouffe, C. (1985). Hegemony \& socialist strategy. Towards a radical democratic politics. London: Verso.

Leirhaug, P. E. (2010). Grepet av natur? - Om friluftsliv, naturvennskap og miljøkrise. I Råd for øko-filosofi: Arven og gleden - et festskrift til naturen (s. 133-140). Trondheim: Tapir akademisk forlag.

Marion, V. P. \& Strømme, A. (2008). Biologididaktikk. Kristiansand: Høyskoleforlaget.

Moen, K. M. \& Frenning, I. (2015). Mye idrett - noe refleksjon - svak kobling: En dokumentanalyse av 30 studiepoeng kroppsøving i grunnskolelærerutdanning 1.-7. trinn. Tidsskriftet FoU i praksis, 9(2), 187-206.

Mortensen, P. (2013). Natur. I L. H. Kjældgaard, L. Møller, D. Ringgaard, L. M. Rösing, P. Simonsen \& M. R. Thomsen (red.), Litteratur. Introduksjon til teori og analyse (s. 279290). Århus: Aarhus Universitetsforlag.

Nasjonalt råd for lærerutdanning (2016a). Nasjonale retningslinjer for grunnskolelæererutdanning trinn 1-7. Hentet fra: https://www.uhr.no/_f/p1/ibda59a76-750c-43f2-b95aa7690820ccf4/revidert-171018-nasjonale-retningslinjer-for-grunnskolelarerutdanningtrinn-1-7 fin.pdf

Nasjonalt råd for lærerutdanning (2016b). Nasjonale retningslinjer for grunnskolelererutdanning trinn 5-10. Hentet fra: https://www.uhr.no/_f/p1/iffeaf9b9-6786-45f5-8f31e384b45195e4/revidert-171018-nasjonale-retningslinjer-for-grunnskoleutdanning-trinn-510 fin.pdf

Nyrnes, A. (2017). Grøn Topologi. Ei nylesing av Vergils hjul. Kultur \& Klasse, 45(123), 269-290. doi: https://doi.org/10.7146/kok.v45i123.96840

Næss, A. (1976). Økologi, samfunn og livsstil. Oslo: Universitetsforlaget.

QSR International Pty Ltd (2017). NVivo qualitative data analysis Software (Version 11).

Quinn, F., Castéra, J. \& Clément, P. (2016). Teachers' conceptions of the environment: anthropocentrism, non-anthropocentrism, anthropomorphism and the place of nature. 
Environmental Education Research, 22(6), 893-917. doi:

https://doi.org/10.1080/13504622.2015.1076767

Rafoss, K. \& Seippel, Ø. (2016). Friluftslivsaktiviteter i den norske befolkningen - en studie av utviklingstrekk og sosiale forskjeller i perioden 1990-2013. I A. Horgen, M. L. Fasting, T. Lundhaug, L. I. Magnussen \& K. Østrem (red.), Ute! Friluftsliv pedagogiske, historiske og sosiologiske perspektiv (s. 185-210). Bergen: Fagbokforlaget.

Rajecki, D.W. (1982). Attitudes: themes and advances. Sunderland, MA: Sinauer.

Røskeland, M. (2018). Natur i litteraturen. Økokritisk litteraturundervisning med døme frå diktsamlinga Eg er eg er eg er. I K. Kverndokken (red.), 101 litteraturdidaktiske grep om å arbeide med skjønnlitteratur og sakprosa (s. 39-56). Bergen: Fagbokforlaget.

Sandell, K. \& Öhman, J. (2010). Educational potentials of encounters with nature: reflections from a Swedish outdoor perspective. Environmental Education Research, 16(1), 113-132. doi: https://doi.org/10.1080/13504620903504065

Sinnes, A. T. \& Straume, I. S. (2017). Bærekraftig utvikling, tverrfaglighet og dybdelæring: fra big ideas til store spørsmål. Acta Didactica, 11(3), Art. 7. doi: http://dx.doi.org/10.5617/adno.4698

Smith, B. H. (2016). What was 'Close Reading'?: A Century of Method in Literary Studies. Minnesota Review, 87 (New Series), 57-75.

Sobel, D. (1996). Beyond Ecophobia: Reclaiming the Heart in Nature Education. Great Barrington, MA: Orion Society.

Straume, I. S. (2017). En menneskeskapt virkelighet. Klimaendring, sosiale forestillinger og pedagogisk filosofi. Oslo: Res Publica.

Stueland, E. (2016). Natur, force majeure og toksiske perspektiv. Økokritiske perspektiv hos Olav H. Hauge. I P. A. Michelsen \& H. Gujord (red.), Norsk litterær årbok (s. 157-179). Oslo: Samlaget.

Sørensen, M. \& Fugl Eskjær, M. (2014). Introduktion. Humanistisk klimaforskning. I M. Sørensen og M. Fugl Eskjær (red.), Klima og mennesker. Humanistiske perspektiv på klimaforandringer (s. 11-21). København: Københavns Universitet Museum Tusculanumus Forlag.

Utdanningsdirektoratet (2015). Læreplan i kroppsøving (KRO1-04). Hentet fra https://www.udir.no/kl06/KRO1-04

Utdanningsdirektoratet (2017). Lærerutdanning 2025. Nasjonal strategi for kvalitet og samarbeid i læererutdanningene. Oslo: Kunnskapsdepartementet. Hentet fra: https://www.regjeringen.no/contentassets/d0c1da83bce94e2da21d5f631bbae817/kd_nasjo nal-strategi-for-larerutdanningene_nett.pdf

Vetlesen, A. J. (2015). The Denial of Nature: Environmental Philosophy in the Era of Global Capitalism. Routledge.

Vetlesen, A. J. \& Willig, R. (2018). Hva skal vi svare våre barn? Oslo: Dreyers forlag.

Williams, R. (1983). Keywords: A vocabulary of culture and society. New York: Oxford University Press.

Wolla, I. Aa. (2015). Utdanning for bærekraftig utvikling i norsk skole - En todelt kvantitativ undersøkelse om ungdomsskoleelever og deres naturfaglcerere. Masteroppgave, Høgskolen i Oslo og Akershus.

World Commission on Environment and Development (1987). Report of the World Commission on Environment and Development: Our Common Future. Hentet fra http://www.un-documents.net/our-common-future.pdf 